\title{
When a joke is more than a joke: humor as a form of networked practice in the Chinese cyber public sphere
}

\author{
Mathew Yates $^{1}$ and Reza Hasmath ${ }^{2^{*}}$
}

\author{
* Correspondence: \\ rhasmath@gmail.com \\ ${ }^{2}$ University of Alberta, Edmonton, \\ $A B$, Canada \\ Full list of author information is \\ available at the end of the article
}

\begin{abstract}
Received wisdom views political humor, viz. egao, in the Chinese cyber public sphere as a form of resistance. This study creates and tests a framework that best conceptualizes how different functions of egao are connected with one another: to analyze the patterns of ties that link the different facets of the phenomenon together. The study contends that by framing egao within network society theory, we can appreciate its fluidity and better understand its online ubiquity. Analysis of survey data suggests that it is not the content solely but the networked practice of egao that dictates its true function. Namely, the networked practices of netizens (Internet citizens) have a formative relationship with their perceptions of, and interactions with, egao. The connectivity netizens feel from engaging in the practice often supersedes its content, in terms of value to cyber culture.
\end{abstract}

Keywords: Political humor, Public opinion, Network society, Netizens, Internet

\section{Introduction}

An individual's emotional response to humor can forge a sense of community with others who likewise share a similar emotional response. For instance, a joke generally requires some relevant background knowledge in order to understand the humor. Take for example the following simple joke: "Did you hear about the party at the Beijing zoo? It was Panda-monium!" Strictly speaking, one must have basic, background knowledge about pandas and the fact that they are predominantly located in China in order to fully appreciate the joke; otherwise, one may continue to be slightly puzzled. The point of fact here is that for those who share similar knowledge of this particular joke, their understanding invokes a similar emotional response of laughter (a sense of humor assumed). As such, an in-group/out-group community is created. This has been elaborated in different contexts, such as studies looking at traditional- vs. cable-based humor (see Baumgartner and Morris 2010, 24-44), or online political humor among youths in the USA (see Baumgartner 2007, 319-338). These studies suggest that those who do possess the background beliefs or inclinations to produce similar emotional responses form an in-group community. In contrast, for those who lack this special bond, mainly due to an absence of the necessary background knowledge, there is an exclusion from the in-group, thereby forming an out-group community. Most poignantly in

(c) The Author(s). 2017 Open Access This article is distributed under the terms of the Creative Commons Attribution 4.0 International License (http://creativecommons.org/licenses/by/4.0/), which permits unrestricted use, distribution, and reproduction in any medium, provided you give appropriate credit to the original author(s) and the source, provide a link to the Creative Commons license, and indicate if changes were made. 
both instances, communities are created and reinforced due to their common emotional responses and similar appreciative values.

This study looks at egao, a humor phenomenon that has rapidly consumed the Chinese cyber public sphere. Egao is a type of spoof, satire, and humor, which often exploits the variety of available homophones in Mandarin Chinese. This contemporary phenomenon has gained notoriety in the form of multimedia mashups, whereby Chinese netizens remix audio, visual, and gaming materials in a satirical spirit.

Definitions of egao fluctuate greatly, varying with an individual's particular stance on the phenomenon. Indeed, Gong and Yang $(2010,4)$ have sought to provide singularity among the multiplicity of meanings and reconciled the various facets of egao together as:

a popular subculture that deconstructs serious themes to entertain people with comedy effects ... the two characters ' $e$ ' meaning 'evil' and 'găo' meaning 'work' combine to describe a phenomenon that is characterized by humor, revelry, subversion, grass-root spontaneity, defiance of authority, mass participation and moot-media high-tech.

This complex and multi-faceted definition suggests egao's inherently fluid character.

Nevertheless, scholarship remains strongly divided over whether egao should be conceived as harmless fun, a site of resistance, and/or a platform for critique. For others, the debate is moot, not worthy of further analytical attention (Leibold 2011, 1023). Preexisting studies of egao have been primarily interested in the political implications of egao, viewing it from the perspective of resistance or control (see Li 2011, 71-88; Tang and Bhattacharya 2011, 11). These analyses have focused on the role of the Internet as a potential vehicle for democratization-a site for forging "the social and cultural foundations for a democratic political system" (Yang 2009, 214), or more broadly, a "safety valve" on issues where the mainstream media set the agenda (Hassid 2012). Such studies have hitherto conceptualized egao in frameworks of power and resistance and tried to determine whether the phenomenon is an "alternative format of political expression" (Meng 2011, 36) and a "weapon of the weak" or a "rather feeble expression among [an] apolitical youth" (Lagerkvist 2010, 151). These divergent approaches have divided scholarship between those such as Tang and Bhattacharya (2011, 2), who refer to the Orwellian tradition that every joke is a "tiny revolution," and others such as $\mathrm{Li}$, who conclude that egao has "limited effectiveness" since it is a "softening critique" of the state-acting as a safety valve by releasing political pressure that could otherwise be potentially destabilizing (Li 2011, 85). Such research has predominantly focused on the contents of egao, conducting textual or visual critical discourse analysis of particular examples of egao in order to assess their meanings and significance (Meng 2011, 33-51; Wallis 2014, 223-238).

Yet, as Meyer highlights, "central to all communication is the audience - to whom a message may be directed" (Meyer 2000, 311). One's ability to assess the function-whether it is political, economic, or social ${ }^{1}$-of online spoof humor is severely limited without first considering how the actual audience interprets it. While these studies have undoubtedly augmented our understanding of the phenomenon, they more often than not reflect a preordained perception of the role of the Chinese cyberspace and do not necessarily capture the entire significance of the phenomenon. For example, a preoccupation 
with control versus freedom neglects the complexity of new media usage in China. Indeed, Leibold posits that these binary approaches to online activity in China have become unduly entangled in an "increasingly stale debate" between digital activism and public opinion management (Leibold 2011, 1023).

However, tempting it may be to assign importance to the political function of egao, eliciting its causality has proven to be a formidable task: interviews with-and surveys of-producers and consumers of egao have led various scholars to note that online wordplay "may be perceived as a form of depoliticization" (Nordin and Richaud 2014, 62); that is, "neither performed to be, nor perceived as, a threat against the Party-state" (Lagerkvist 2010, 158). The fact that the debate has reached such an impasse or, in Leibold's terms, has become so "stale" suggests that a different approach to understanding the functions of egao is needed.

In this unpropitious background, this study posits that egao should also be analyzed as a socio-cultural practice through empirical research and not solely through the political lens that has dominated analysis. Given the inherent potential for jokes and humor to foster communities that can form an in-group/out-group dualism, there is an urgent need to create and test a framework that best conceptualizes how different functions or facets of egao are connected with one another and to analyze the patterns of ties that link the different facets together. ${ }^{2}$ It is the contention of this study that by framing egao within a network society theory, we can adequately appreciate its fluidity and, hence, begin to understand its online ubiquity. Such a theory enables analysis to conceptualize egao as a process (i.e., a networked practice) rather than a static concept; it frames egao both as a socio-cultural expression and a potential form of political critique. Furthermore, network society theory recognizes the centrality of digital technologies, such as the Internet, in facilitating the recent upsurge in the production and circulation of egao.

\section{Theoretical framework}

The network society was first popularized by Stein Braten (1981) in his 1981 landmark monograph, Modeller Av Menneske Og Samfunn (Model of Man and Society), which built upon Martin's (1978) "wired society" concept At the most basic level, both theorists argue that a network society is one where key social, economic, and political structural changes are influenced/caused by the spread of networked, digital information and communication technologies. More recent theorists have provided greater nuance to this understanding by looking at new media. Van Dijk suggests that society is increasingly organizing its relationships with new media networks to the extent that it is replacing or complementing the social networks of face-to-face communication (Van Dijk 1991 and 2006). This observation is supported by Castells who argue that such networks "constitute the new social morphology of our societies" (Castells 1996, 469). He writes:

The new power [in network society] lies in the codes of information and in the images of representation around which societies organize their institutions, and people build their lives, and decide their behavior (Castells 1997, 359).

At its core, a network society is one whose structures are made up of networks powered by microelectronic-based information and communication technologies (Castells and Kreisler 2001). A network can be defined as a "collection of links between elements 
of a [social] unit" (Van Dijk 2006, 24) or a series of interconnected nodes. A single link of two nodes-or elements-is called a relationship, whereas in a network, the smallest number of links is two. In Castells' $(2004,3)$ words, a "network has no centre, just nodes." It should be understood as a social structure made up of a set of interconnected social actors at different levels in the network, such as an individual or organization. Like Castells, Van Dijk suggests that it is vital to understand network society in terms of levels of networking, e.g., the personality of an individual, the measure of formality of a group, the extent of centralization of an organization, or the phase of development of a society (Van Dijk 2006, 27).

It should be noted that both Castells and Van Dijk vehemently disagreed over the degree and extent to which modern society has become a network society. For Van Dijk (2006, 241) "modern society is in a process of becoming a network society ... it is in a transition from mass to network society." For Castells, however, this transition has already taken place, and the network has since become the basic unit of society. While eliciting to what extent modern society is or is becoming a network society falls outside the parameters of this study, we can say with confidence that the network work society concept best captures the fluidity of egao and how different actors interact at different levels of connectivity.

This can be mapped out to various levels of the network society. The individual level corresponds to ties between family members, friends, acquaintances, neighbors, colleagues, etc. Suffice to say, this level is supported and intensified by the rise of the media networks. Beyond the individual level is the group/organizational level and its societal relations. Whereby individuals, groups, and organizations shape a society that is built on, and linked by, social and media networks, these networks link people to bodies and institutions of the state and foster relationships with groups of citizens and (semi-)autonomous or private organizations. Finally, global networks, bolstered by international broadcasting, telecommunications, and computer networking, are created through an expansion of societal and group networks into the arena of international relations.

While instances of the adoption of wordplay to circumvent public opinion management in China can be traced back to the imperial era, Gong and Yang (2010) are keen to emphasize the role played by technology in the widespread proliferation of egao in the digital age of contemporary China. Thus, they examine egao as a new technologyenabled cultural intervention. They argue that egao is a product of the twenty-first century digital technologies, since egao "requires knowledge of and skills in textual, audio, and video editing ... [and] is predominantly made by individuals using digital technologies on personal computers" (Gong and Yang 2010, 5-6). In short, it is necessary to drive our analysis with network society theory, which inherently recognizes that the rapid development of digital communications and information technologies can cause social, economic, and political structural changes.

\section{Methods}

An online survey, in Mandarin Chinese, was conducted in mainland China by the researchers between April 5 and 19, 2015, probing into how egao is perceived and why netizens might view and/or share it in the Chinese cyber public sphere. Following Van Selm and Jankowski's advice for online surveys, a combination of open and closed 
questions were posed to participants (Van Selm and Jankowski 2006, 435-456). Eleven questions asked participants to indicate their agreement or disagreement towards a particular statement on egao using a progressive a 7-option Likert scale (LS). Half of the 11 LS questions asked respondents to explain why they answered in their chosen manner. The survey contained three fully open-ended questions that sought to capture the respondent's feelings towards egao in the most flexible way possible. In addition, participants were asked to indicate five demographic variables: age group, gender, educational attainment, monthly income, and party affiliation. A detailed breakdown of these groups is documented in Table 1 . The sample corresponded with the general demographic background of netizens in China and reflected the typical characteristics of Chinese netizens as indicated by Wang (2013). In other words, our sample are dominated by males $(58.1 \%)$, young persons ( $79.4 \%$ are under the age of 30$)$, and universityeducated individuals (93.1\%). Given most active participants of online egao culture are a particular cohort of Chinese society, it should be fully emphasized that our analysis does not capture demographics beyond this cohort and individuals who may consume egao via traditional print media.

The survey included several examples of egao-see Fig. 1. The examples were chosen to ensure that different facets of egao were visible and represented and to further aid recall. The survey included images from Hu Ge's "The Bloody Case That Started with a Steamed Bun" (Yīgè mántou y̌̆nfā de xuè’àn) parody video, based on the film "The Promise." $\mathrm{Hu}$ Ge is accredited with "kicking off" the egao craze in 2005, and his

Table 1 Descriptive sample

\begin{tabular}{|c|c|c|c|c|c|c|}
\hline & & Number & Percent & Mean & SD & Median \\
\hline \multirow[t]{3}{*}{ Gender } & Male & 118 & 58.1 & & & \\
\hline & Female & 85 & 41.9 & & & \\
\hline & Total & 203 & 100 & & & \\
\hline \multirow[t]{5}{*}{ Age group } & $18-23$ & 51 & 25.1 & & & \\
\hline & $24-29$ & 100 & 49.3 & & & \\
\hline & $30-35$ & 39 & 19.2 & & & \\
\hline & $36+$ & 13 & 6.4 & & & \\
\hline & Total & 203 & 100 & 2.07 & 0.84 & 2.00 \\
\hline \multirow[t]{4}{*}{ Educational attainment } & High school level or below & 14 & 6.9 & & & \\
\hline & Undergraduate level & 148 & 72.9 & & & \\
\hline & Postgraduate level or higher & 41 & 20.2 & & & \\
\hline & Total & 203 & 100 & 2.13 & 0.50 & 2.00 \\
\hline \multirow[t]{5}{*}{ Monthly income $\left(\right.$ 元 $^{a}$ ) } & Less than 3,000元 & 71 & 35.0 & & & \\
\hline & $3001-6,000$ 元 & 70 & 34.5 & & & \\
\hline & $6001-9,000$ 元 & 34 & 16.7 & & & \\
\hline & 9,000 元 + & 24 & 11.8 & & & \\
\hline & Total & 203 & 100 & 2.06 & 1.01 & 2.00 \\
\hline \multirow[t]{4}{*}{ Political affiliation } & Party member & 29 & 14.3 & & & \\
\hline & Communist youth league & 94 & 46.3 & & & \\
\hline & Non-party & 80 & 39.4 & & & \\
\hline & Total & 203 & 100 & 2.25 & 0.69 & 2.00 \\
\hline
\end{tabular}

${ }^{\mathrm{a}} 1 \mathrm{RMB}$ (元) $=0.16$ USD 

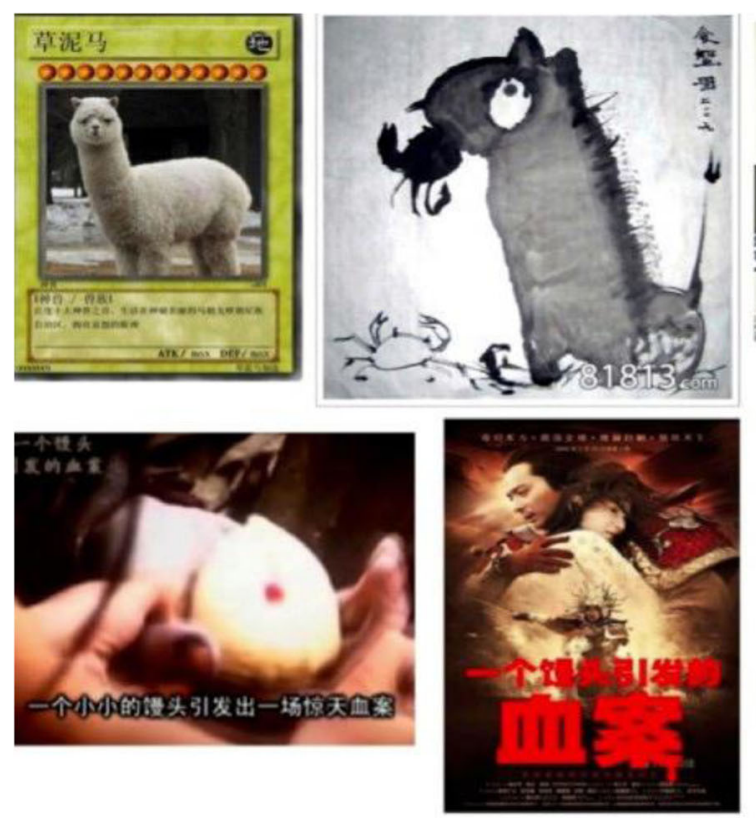

Fig. 1 Examples of egao presented to participants at the beginning of the survey
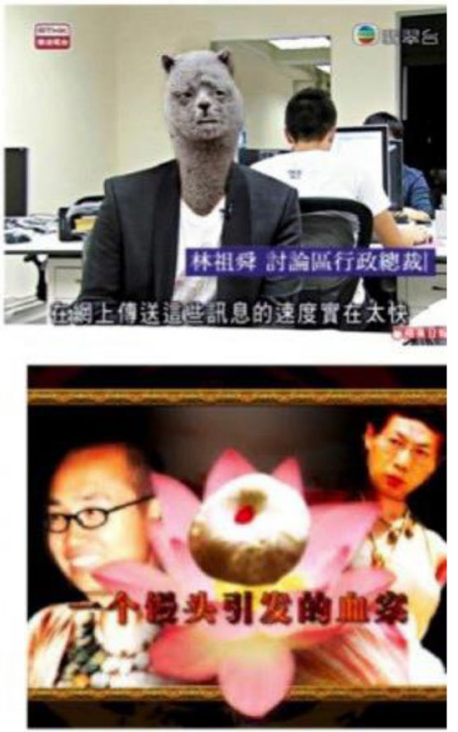

multimedia mash up of "The Promise" was seen by tens of millions of netizens. $\mathrm{Hu} \mathrm{Ge}$ was keen to assert that the sole purpose of his video was entertainment, noting that he did not have any political motives and merely sought to rebel against the serious. In contrast, other examples utilized in the survey were more overtly political in nature. The "Grass Mud Horse" is perhaps the most famous of all egao; it was a direct grass-roots response to the "Anti-Vulgarity" online campaign, which had been launched in early 2009 with a strict purpose of cleaning up the Internet. "Grass Mud Horse" plays on the Mandarin phrase càonı̌mā (literally " $\mathrm{f}$ "* $\mathrm{k}$ your mother") and has in turn become a symbol of the egao movement, both inside and outside of China, appearing in numerous academic and popular writings on egao (See Xiao 2011, 47-61). In certain images, another mythical creature, the "River Crab," accompanies the "Grass Mud Horse." This specifically plays on the "harmonious" social discourse prevalent during the period, where netizens had previously appropriated "harmony" as euphemism for social opinion management. "River Crab" (héxiè) sounds similar in Chinese to "harmonious" (héxié) and is fitting since a "crab" is also a bully.

The lack of a traditional sampling frame is a common shortfall for online social network studies (see Gjoka et al. 2011, 1893-1905; Kaye and Johnson 1999, 325). Traditional random sampling techniques are near impossible for an online platform and notably so within the Chinese context. As a result, Internet researchers have often taken to the adoption of web crawling and snowballing as a viable alternative. The latter, a snowballing sampling technique, was employed, asking participants to distribute the survey among their online community. While snowballing techniques can potentially lead to path dependence, selection, and/or gatekeeper bias (see Atkinson and Flint 2001, 1-4), this was the most effective way to obtain the relevant information, and as mentioned, our sample in the end corresponded with the general demographic background of netizens in China. 
A survey invitation was posted on a widely used online social "crowd-sourcing" platform, Zhubajie.com, which broadcasted the invitation to its millions of members. Furthermore, the invitation was posted on Weibo (China's primary social networking website, akin to Twitter), inviting users to complete the survey. The invitation also asked Weibo users to distribute the request across their social networks. The invitation letter contained a link to the survey, hosted by the website, Survey Monkey. ${ }^{3}$ Through IP address tracking, we were able to validate that the participants were located in mainland China and were only able to complete the survey once.

A total of 227 valid individual responses were received, which constituted a significant repository of data: there were, in total, 2494 responses to the 14 questions (inclusive of 11 LS questions and 3 open-ended questions) and 2721 quantifiable responses to the 11 LS questions alone. Data analysis was collated in three steps.

First, we performed a descriptive analysis of both the quantitative and qualitative data. We sought to highlight the main themes that emerged from the survey data and in turn explore how and where these themes can be situated within existing scholarship, as discussed in the previous section. It is at this stage that we mapped out the various nodes of egao, which include its function as a social lubricant, a vehicle for entertainment, and a form of resistance. Analysis at this level showed, in general, how respondents perceive egao and what they consider to be the most important aspect of egao. Further, the mapping process involved coding the responses to the open-ended questions by identifying thematic word usage. Thematic analysis of the open-ended questions enabled us to identify the key functions of egao as perceived by respondents. We were subsequently able to divide the responses into groups, depending upon how the respondents perceived the phenomenon.

The second part of the analysis examined how these particular groups responded to questions in the survey, and examined what, if any, relationship exists between the groups, seeking to "analyze the patterns of ties linking the nodes" in the data (Wellman 1983, 157). This phase of the analysis, embedded squarely in network society theory, sought to explain the connectivity between the groups and patterns in the data. Here, we drew primarily upon the numerical data in the survey and sought to document the numerical trends in the groups. Since there was no existing research using a similar framework to analyze how Chinese netizens perceive and engage with egao, meaningful comparison of the trends in this data with other studies was not possible. We therefore conducted one-sample $T$ tests to compare the mean results of the particular groups identified with the averages of the overall data set. Furthermore, we carried out logic function trials on the dataset to test how many times the patterns identified in the data were "True" or "False."

The final phase of the analysis looked at the implications of the patterns identified.

We sought to determine whether-and if so, to what degree-individual variables can be manipulated to predict greater trends in the overall data. Again, we utilized network society theory in order to characterize the trends that emerged in the data. This enabled us to collate the three major aspects of the data analysis and thus identify potential avenues for future scholarship on egao.

Before we continue, it is important to briefly recognize the inherent limitations of the study. First, the survey participants completed the survey in the context of stringent media regulations-this would have likely been at least a minor consideration for 
respondents completing the survey. Second, while the examples presented to respondents at the beginning of the survey were some of the most famous manifestations of the phenomenon-potentially displaying egao's political, social, and cultural facets-it is likely that not all of the respondents recognized their true underlying significance in the movement. Furthermore, these examples were mainly still images, with some accompanying text. Egao is well known for utilizing a variety of mediums in its creation and dissemination; we must therefore entertain the possibility that participants may have responded differently to other media formats.

\section{Findings and discussion}

The survey asked participants to explain their perception of the purpose of egao (see Table 2). The data were, unsurprisingly, exceptionally varied, exemplified by the high standard deviation values. Many qualitative responses reinforced this trend, with respondents writing that egao was "purely for fun" and to "bring happiness to their friends" and engage with a "fun spirit," while others stated that egao was a "clever method of circumvention" allowing netizens to "satirize [social] phenomenon".

The data were organized thematically-following Hine (2004) Guidelines ${ }^{4}$ - highlighting the close associations between the categories, as many participants identified more than one function in their response. Indeed, 226 potential themes were identified in total among the respondents. We therefore collapsed the qualitative data-which was cross-checked with the quantitative data-into three main categories ${ }^{5}$ :

Group 1: individual level $(n=112)$

Respondents in group 1 indicated that egao's purpose was purely to either entertain and/or allow connections at the individual level. That is, to make friends, family, or classmates laugh or make connections at this level aware of their anger/opinion on a particular issue.

Table 2 Summary of survey responses

\begin{tabular}{|c|c|c|c|c|}
\hline & Number & Mean & $S D^{a}$ & Median \\
\hline Egao, such as the example images above, is entertaining. & 203 & 4.7 & 1.2 & 5.0 \\
\hline It is important for egao to be humorous. & 203 & 5.7 & 1.1 & 6.0 \\
\hline Egao is immoral; it can be damaging and harmful. & 203 & 3.6 & 1.2 & 4.0 \\
\hline Egao is a type of cultural expression. & 203 & 4.2 & 1.4 & 4.0 \\
\hline Egao is a distinctly Chinese cultural expression. & 203 & 3.8 & 1.4 & 4.0 \\
\hline Creating, sharing, or viewing egao can make me feel Chinese. & 203 & 3.3 & 1.4 & 3.0 \\
\hline Egao can be an effective emotional outlet. & 203 & 5.0 & 1.2 & 5.0 \\
\hline Egao is creative. & 203 & 5.2 & 1.1 & 5.0 \\
\hline Egao can resist and critique official political and social discourses & 203 & 3.6 & 1.6 & 4.0 \\
\hline $\begin{array}{l}\text { Egao takes advantage of modern technology to allow people to } \\
\text { define their position in society. }\end{array}$ & 203 & 4.1 & 1.5 & 4.0 \\
\hline Egao provides all members of society with a voice to express themselves. & 203 & 4.4 & 1.3 & 5.0 \\
\hline
\end{tabular}

Responses are based on a Likert scale from 1 (strongly disagree) to 7 (strongly agree) ${ }^{\text {a } S D ~ s t a n d a r d ~ d e v i a t i o n ~}$ 
Group 2: beyond individual (societal) level $(n=74)$

Respondents in group 2 indicated that egao's function was not just to entertain but to connect participants at a level surpassing the individual; that is, they included references to attract the attention of the public, gain wider publicity online, and participate in societal critique or ridicule. Certain answers also alluded to network/Internet connectivity between participants of egao.

Group 3: political $(n=17)$

Respondents in group 3 indicated that egao's function was primarily political. While those in this group acknowledged egao's role in entertaining citizens, they lamented the existence of online public opinion management. Hence, "speaking the truth" and "speaking freely" were key themes that ran throughout the discourse, along with references to public opinion management, freedom of speech, and political satire.

The data illustrates that egao's primary role is to entertain: $69.5 \%$ of responses featured an explicit reference to egao's role as a vehicle of entertainment in some shape or form. ${ }^{6}$ Indeed, those that did not refer to entertainment explicitly in question one, later agreed that it was important for egao to be humorous (arguably a form of entertainment in its own right) in question 3. Categorizing entertainment into its own group did not, therefore, enhance analysis or reveal any other discernable trends in the data.

Of particular analytical interest were the comments that often accompanied references to egao's entertaining role. Respondents stated, in varying levels of detail, that egao could connect netizens at an individual, group, or even societal level and could function as a type of personal, societal, or, in some instances, political critique. Dividing respondents into these three groups therefore reveals some intriguing trends in the data and furnished an explanation-within the construct of our theoretical framework-why, for instance, the respondents who felt that egao primarily served to entertain and connect at the individual level most strongly disagreed with the notion of egao as a "type of cultural expression" or a critique of official political and social discourses.

\section{Mapping the nodes: a networked social practice}

Group 1 did not see egao serving a political or societal critique, nor did they believe it had an overt sense of connectivity at a larger societal or global group level. Following Van Dijk's concept of the individual network, they saw the egao as a mechanism to foster ties with friends, family, and classmates. This observation suggests that the practices of online satire can be full of creativity, but not always about resistance. In other words, egao can be about building or maintaining personal relationships, rather than fostering a political or social critique. Egao can act as a social platform for netizens and communities of netizens who are eager to express themselves and connect with others in entertaining ways. It ultimately provides an occasion for personal expression and social interaction while lubricating relationships online.

Nevertheless, it is necessary to concede that some of the respondents who stated that egao was appropriated purely for purposes of entertainment at the individual level may have done so due to the brevity and ease of adopting such a response. We have sought to address this issue by ensuring that the trends discussed in the qualitative data are consistent with those in the quantitative data. For example, we would expect a sizeable 
proportion of the $55.2 \%$ of participants in group 1 , who did not allude to a political or societal function of egao, to contest the statement that "egao can critique official social or political discourses". Thus, cross-examining the two trends in the data can validate this claim.

Table 3 shows that the respondents in group 1 most strongly agreed that it was important for egao to be humorous (m: 5.8). Yet, when compared with the other survey respondents, it is evident that they did not feel that egao was a type of cultural expression nor did they feel that citizens and netizens use it to define and express their position in society. It should be noted that this group most strongly disagreed that egao can furnish a critique of official political discourses. Given that egao is not perceived to be inherently political by the majority of survey respondents in this category, future scholarship should perhaps aim towards-or at least feature-socio-cultural analyses. Thus, while it may be misguided to regard egao as entirely apolitical, it is inherently problematic to conceptualize the phenomenon as a form of political resistance, as many studies have done, notably given that only $8.8 \%$ of respondents explicitly indicated that they felt egao serves a political function.

Egao can be used to subtly critique the state, appropriating official language and then re-inscribing it in other discourses of meaning to, make "sophisticated critiques of the regime without encountering harsh repression" (Esarey and Xiao 2008, 752). Yet in being so subtle, egao risks many netizens misunderstanding the particular brand of humor and subsequently overlooking its core message. The examples shown to participants at the beginning of the survey were not apolitical; they featured some of the most famous and widespread online critiques of public opinion management. While certain users were attuned to the political resonance of these particular examples (group 3), the vast majority of survey respondents overlooked any potential political undertones or implications of the egao on display. Indeed, Lagerkvist (2010, 146), one of the few writers on egao who has interviewed netizens on the topic, remains highly skeptical about conceptualizing egao primarily as a form of political resistance, believing that the critique is often "too subtle" to serve a political function, as many netizens do not identify with the underlying message in these instances of egao.

Table 3 Comparison of quantitative responses by group

\begin{tabular}{|c|c|c|c|}
\hline & Group $1(n=112)$ & Group $2(n=74)$ & Group $3(n=17)$ \\
\hline $\begin{array}{l}\text { Egao, such as the example images above, is } \\
\text { entertaining. }\end{array}$ & 4.7 & 4.7 & 4.5 \\
\hline It is important for egao to be humorous. & 5.8 & 5.6 & 5.6 \\
\hline Egao is immoral; it can be damaging and harmful. & 3.6 & 3.7 & 3.6 \\
\hline Egao is a type of cultural expression. & 3.5 & 4.8 & 5.7 \\
\hline Egao is a distinctly Chinese cultural expression. & 3.3 & 4.7 & 2.4 \\
\hline $\begin{array}{l}\text { Creating, sharing, or viewing egao can make me } \\
\text { feel Chinese. }\end{array}$ & 3.0 & 4.1 & 2.2 \\
\hline Egao can be an effective emotional outlet. & 4.9 & 5.1 & 5.5 \\
\hline Egao is creative. & 5.1 & 5.2 & 5.3 \\
\hline $\begin{array}{l}\text { Egao can resist and critique official political and } \\
\text { social discourses. }\end{array}$ & 2.9 & 4.2 & 6.1 \\
\hline $\begin{array}{l}\text { Egao takes advantage of modern technology to } \\
\text { allow people to define their position in society. }\end{array}$ & 3.8 & 4.2 & 6.2 \\
\hline $\begin{array}{l}\text { Egao provides all members of society with a voice } \\
\text { to express themselves. }\end{array}$ & 4.1 & 4.7 & 5.4 \\
\hline
\end{tabular}


Jokes and multimedia mashups, irrespective of their political importance, enjoy widespread circulation online circulation because they act as a social medium. Mashups are a networked social practice and offer a means of socially connecting with other cyberspace users at a group, societal, or global level. Egao is, for the majority of respondents to the survey, a social practice that connects them to existing nodes in their individual networks. Online users share and create egao to augment their ties with friends, family, and classmates, and as such, they do not appear to aspire to a wider connectivity through their engagement with the practice. Even if the same instance of egao is shared many times online, across many different individual networks, its meaning does not necessarily remain the same throughout; the egao itself does not necessarily connect these networks together, i.e., it is not the content that creates a group/societal/global network. Hence, it is not the content of egao that gives egao its meaning, as users are able to embed their own meaning from new contexts into it. Evidently, egao can be created with a specific political purpose in mind but be later shared by online users with apolitical motivations. It would be misguided to assume that just because egao can connect netizens above the individual level, and can resist official political and social discourses, that these capabilities are being realized in practice. Egao is first and foremost a networked social practice to connect netizens at an individual level. It ultimately provides an occasion for personal expression and social interaction while lubricating relationships online.

\section{This is network culture}

Conceptualizing egao as a networked practice can also help explain why egao's function often surpasses pure entertainment. Both groups 2 and 3 alluded to a connectivity that transcends the individual level. These respondents did not refer to family, friends, or classmates but instead cited societal networks-cultivated with the intent of connecting "Chinese with Chinese" and reference a wider cyber space/network culture. Indeed, many participants discussed examples of other types of Chinese humor, such as crosstalk (xiàngsheng). Suffice to say, groups 2 and 3 perceived egao as a form of cultural expression. Indeed, Table 3 shows that these groups strongly agreed with the statement "egao is a type of cultural expression" (G1 m: 3.5, G2 m: 4.8, G3 m: 5.7).

Both Castells and Van Dijk demonstrate how networked practices can lead to the formation of cultural identities, connecting users in virtual communities online (Castells 2004; Van Dijk 2006). Since culture is enacted through communication, culture itself can be transformed and shaped by new technological systems, such as the Internet. In this vein, egao can be a site where cultural transformation and social stratification intersect through digital technologies (Gong and Yang 2010,4). The conditions in which egao has flourished have rendered it a distinctly Chinese cultural phenomenon, which often appropriates the variety of available homophones in Mandarin Chinese to entertain netizens. Yet, it is at this node, when conceptualizing egao as a cultural practice in the network society, that some particularly revealing trends and patterns emerge in the data.

While respondents in groups 2 and 3 agreed that egao was a "type of cultural expression" ( $\mathrm{m}: 4.8$ and $\mathrm{m}: 5.7$, respectively), they contested the meaning of "type of cultural expression." Table 3 illustrates that group 2 also agreed that egao was a "distinctly Chinese cultural expression" (m: 4.7) and more strongly agreed that creating, viewing, or sharing egao can 
"make [one] feel Chinese" (m: 4.1). In contrast, while group 3 more strongly agreed than group 2 that egao was a type of cultural expression, they disagreed that egao was a distinctly Chinese cultural expression ( $\mathrm{m}: 2.4)$ and strongly disagreed that creating, sharing, or viewing egao made them feel Chinese ( $\mathrm{m}: 2.2)$. Indeed, a logic function test (see Table 4) of the three groups illustrates that $85 \%$ of participants in group 3 agreed that egao was a type of cultural expression, but not a distinctly Chinese cultural expression. In contrast, only $19 \%$ of group 2 rejected the idea of egao as a distinctly Chinese cultural expression. The majority of group $2(53 \%)$ felt that egao was a distinctly Chinese cultural phenomenon.

Respondents in group 3 were keen to emphasize that egao was a "modern," "new," "technological," and "Internet" form of culture. Certain respondents stated that egao represented a network culture, keen to emphasize the existence of similar humor culture in other nations such as the USA and Japan. Respondents pointed to references to American programs such as "The Daily Show" (under the former stewardship of Jon Stewart) and comedy roasts. In addition, many similarities were drawn between egao and Japanese kuso culture. In particular, Japanese and Chinese cultures share many traditions, and their use of characters and tones creates an availability of homophones (Greene 2011; Nordin and Richaud 2014,47-67).

A comparative analysis of egao and American/Japanese parody humor could further highlight the connective feature(s) of this satirical brand of humor. Castells proposes that networked practices can be a "communication between different cultures on the basis, not necessarily of shared values, but of sharing the value of communication" (Castells 2004, 39). Indeed, Qiu (2004, 114) notes that the process by which Chinese netizens express themselves and construct their online identities "bears both Chinese and universal characteristics".

Egao's perceived global character has ultimately played a significant role in facilitating online resistance to and critique of the state. Indeed, the findings of this study would certainly suggest that it is egao's connectivity that determines its function. While certain academic writers have sought to explore parody and satire across the globe, they are yet to turn their cross-cultural gaze to China (see Baym and Jones 2013). Evidently, there are significant grounds for realignment in the geographic scope of scholarship on egao.

The respondents in group 3 showed an acute awareness of other cultures that use similar kinds of humor. This suggests that an awareness of others is a necessary prerequisite for netizens to consider the networked practice of egao a form of resistance. This further implies that the networked practices of netizens have a formative relationship with their perceptions of, and interactions with, egao. The more connected netizens feel, the more likely they are to perceive egao as an active vehicle for societal or political critique. Again, the perception of the egao is contingent upon its production and dissemination within a particular network rather than the nature of its content. This article therefore posits that

Table 4 Logic function table

\begin{tabular}{llll}
\hline Question scenarios $^{\mathrm{a}}$ & Group 1 (\%) & Group 2 (\%) & Group 3 (\%) \\
\hline Agreed A, agreed B & 20.1 & 53.1 & 5.0 \\
Agreed A, disagreed B & 21.1 & 19.5 & 85.0 \\
Disagreed A, agreed B & 17.0 & 12.3 & 0.0 \\
Disagreed A, disagreed B & 41.8 & 15.1 & 10.0 \\
\hline
\end{tabular}

A "Egao is a type of cultural expression", B "Egao is a distinctly Chinese cultural expression" ${ }^{a}$ Neither agree nor disagree was counted as both agree and disagree in the function 
scholars should aim to examine the network practices-both on- and offline-of netizens when trying to understand the function of egao in China.

\section{Conclusion}

This study has shown that conceptualizing egao as a networked practice, by shifting analysis away from content to practice, will only serve to complement our understanding of the phenomenon. While it is misguided to regard egao as entirely apolitical, it is inherently problematic to conceptualize the phenomenon solely as a form of political resistance. Indeed, the Chinese cyber public sphere is not a superimposed agent of change but a conduit through which the existing tendencies of Chinese society can be advanced.

This article has utilized sustained thematic and statistical analysis to demonstrate that a relationship exists between the perceived connectivity and function of egao. The perception of egao is ultimately contingent upon its production and dissemination within particular networks, rather than the nature of its content.

While the primary purpose of this study has been to identify and accumulate new forms of knowledge pertaining to egao, its secondary function has been to uncover unknowns in scholarship. Our findings will hopefully serve as a platform for further research on the phenomenon. Suffice to say, a phenomenon with a "multiplicity of meanings" is worthy of an equally diverse approach from scholars. By mapping out the interconnectivity of egao's various nodes, we can begin to unite the many diverse aspects of a debate that has hitherto appeared "stale" and irreconcilable.

\section{Endnotes}

${ }^{1}$ While we can disaggregate the individual political, economic, and social functions of a particular humorous content for analytical purposes, there are limitations to this exercise since these functions can be interwoven and intertwined at a deep, intrinsic level-and to an extent, not known to the producer and receiver of the content.

${ }^{2}$ One does not necessarily need to create egao to be a part of the practice. Indeed, Yang and Jiang argue that the sharing and circulation of a joke is more important than its creation and content (Yang and Jiang 2015, 216). This is reinforced by Cook and Hasmath $(2014,979)$ who suggest in their study that it is a commonplace that Internet users "embed new utterances which did not originate with them within new contexts."

${ }^{3}$ There is a plethora of academic research conducted in China using Survey Monkey (see for example, Wang 2013). From another standpoint, Sheehan and McMillan in their review of online surveys found that respondents seemed much more willing to reply to open-ended questions in an online format than in traditional paper surveys (Sheehan and McMillan 1999, 45-54)

${ }^{4}$ This included both electronic methods, such as specific keyword searching, and manual methods, where a start list of potential codes was generated from reading and re-reading the data.

${ }^{5}$ As some responses featured multiple themes, the total number of themes exceeds the total number of respondents. Further, 22 responses could not be thematically coded.

${ }^{6}$ We categorized the following terms as entertainment: "amuse," "entertain," "happiness," "joke," and "laugh." 
Competing interests

The authors declare that they have no competing interests.

Consent for Publication

Written consent was obtained by participants for this study, and for the use of any accompanying images.

\section{Publisher's Note}

Springer Nature remains neutral with regard to jurisdictional claims in published maps and institutional affiliations.

\section{Author details}

${ }^{1}$ University of Oxford, Oxford, UK. ${ }^{2}$ University of Alberta, Edmonton, AB, Canada.

Received: 21 April 2017 Accepted: 4 December 2017

Published online: 14 December 2017

\section{References}

Atkinson, R., and J. Flint. 2001. Accessing hidden and hard-to-reach populations: snowball research strategies. Soc Res Update 33: 1-4.

Baumgartner, J.C. 2007. Humor on the next frontier youth, online political humor, and the JibJab effect. Social Science Computer Review 25 (3): 319-338.

Baumgartner, J.C., and J.S. Morris. 2010. MyFaceTube politics: social networking web sites and political engagement of young adults. Social Science Computer Review 28 (1): 24-44.

Baym, G., and J.P. Jones. 2013. News parody and political satire across the globe. London: Routledge.

Braten, S. 1981. Modeller Av Menneske Og Samfunn. Oslo: Universitetsforlaget.

Castells, M. 1996. The rise of the network society. Malden: Blackwell.

Castells, M. 1997. The power of identity. Malden: Blackwell.

Castells, M. 2004. The network society: a cross-cultural perspective. Cheltenham: Edward Elgar.

Castells, M., and H. Kreisler. 2001. Identity and change in the network society: conversation with Manuel Castells. Berkeley: Conversations With History, Institute Of International Studies, University of California Available at: http:// globetrotter.berkeley.edu/people/Castells/castells-con4.html.

Cook, J., and R. Hasmath. 2014. The discursive construction and performance of gendered identity on social media. Current Sociology 62 (7): 975-993.

Esarey, A., and Q. Xiao. 2008. Political expression in the Chinese blogosphere: below the radar. Asian Surv 48 (5): 752-772.

Gjoka, M., C.T. Butts, M. Kurant, and A. Markopoulou. 2011. Multigraph sampling of online social networks. IEEE J. Select. Areas Commun 29 (9): 1893-1905

Gong, H., and X. Yang. 2010. Digitized parody: the politics of egao in contemporary China. China Inf 24 (1): 3-26.

Greene, R.L. 2011. Fă Kè Yóu, river crab. The Economist Available at: http://www.economist.com/blogs/prospero/2011/ 06/chinese-censorship.June 7.

Hassid, J. 2012. Safety valve or pressure cooker? Blogs in Chinese political life. The Journal of Communication 62 (2): $212-230$

Hine, C. 2004. Social research methods and the Internet: a thematic review. Sociological Research Online 9 (2).

Kaye, B.K., and T.J. Johnson. 1999. Research methodology: taming the cyber frontier: techniques for improving online surveys. Social Science Computer Review 17 (3): 323-337.

Lagerkvist, J. 2010. After the Internet, before democracy. Bern: Peter Lang.

Leibold, J. 2011. Blogging alone: China, the Internet, and the democratic illusion? J Asian Stud 70 (4): 1023-1041.

$\mathrm{Li}, \mathrm{H}$. 2011. Parody and resistance on the Chinese Internet. In Online society in China: creating, celebrating, and instrumentalising the online carnival, ed. D.K. Herold and P. Marolt, 71-88. Oxford and New York: Routledge.

Martin, J. 1978. The wired society. Englewood Cliffs: Prentice-Hall.

Meng, B. 2011. From steamed bun to grass mud horse: egao as alternative political discourse on the Chinese Internet. Global Media Commun 7 (1): 33-51.

Meyer, J.C. 2000. Humor as a double-edged sword: four functions of humor in communication. Communication Theory 10 (3): 310-331.

Nordin, A., and L. Richaud. 2014. Subverting official language and discourse in China? Type River crab for harmony. China Inf 28 (1): 47-67.

Qiu, J.L. 2004. The Internet in China: technologies of freedom in a statist society. In The network society: a cross-cultural perspective, ed. M. Castells, 99-125. Cheltenham: Edward Elgar.

Sheehan, K.B., and S.J. McMillan. 1999. Response variation in e-mail surveys: an exploration. Journal of Advertising Research 39 (4): 45-54.

Tang, L., and S. Bhattacharya. 2011. Power and resistance: a case study of satire on the Internet. Sociological Research Online 16 (2): 11.

Van Dijk, J.A.G.M. 1991. De Netwerkmaatschappij. Houten: Bohn Stafleu Van Loghum.

Van Dijk, J.A.G.M. 2006. The network society. London: Sage.

Van Selm, M., and N.W. Jankowski. 2006. Conducting online surveys. Qual Quantity 40 (3): 435-456.

Wallis, C. 2014. Gender and China's online censorship protest culture. Feminist Media Stud 15 (2): 223-238.

Wang, W. 2013. The influence of Weibo political participations on the political efficacies of Weibo users. London: LSE Series on Global Media and Communication

Wellman, B. 1983. Network analysis: some basic principles. Sociological Theory 1: 155-200.

Xiao, Q. 2011. Liberation technology: the battle for China's Internet. J Democracy 22 (2): 47-61.

Yang, G. 2009. The power of the Internet in China. New York: Columbia University Press.

Yang, G., and M. Jiang. 2015. The networked practice of online political satire in China: between ritual and resistance Int Commun Gazette 77 (3): 215-231. 